\section{On: Milgrom LR: Under pressure: homeopathy UK and its detractors. Forsch Komplementmed 2009;16:256-261}

Milgrom's article was certainly the most amusing, uplifting and revealing bit of alternative fiction I have read for a very long time. Amusing because the arguments of the authors are truly funny. I am on the top of the 'Big Pharma' iceberg trying to crush homeopathy!?! Why would 'Big Pharm' bother? Homeopathy only amounts to $0.006 \%$ of the total National Health Service (NHS) budget, as Milgrom points out. Where is the evidence that my pockets are being lined by Big Pharma? Where is the evidence that the media are out to get homeopathy? The truth is that the media are, on average, pro not contra! [1]

The article is uplifting because it shows how incredibly weak the arguments of homeopaths really are. Just one example: even if water has a memory and homeopathic water is in this or that way different from non-homeopathic water, how does it affect a cure? The water in my kitchen sink is also different in many ways from pure water, but I wouldn't advocate it as a medicine! And if the memory of water theory is correct, how do homeopathic globuli work? Never mind logical positivism, logic would already go a long way.

Finally, Milgrom's article is revealing. Implying that the detractors of homeopathy are bribed by 'Big Pharma' is one thing, not disclosing one's relationship to manufacturers of homeopathic remedies when writing such an article is, according to accepted standards [2], a breach of publication ethics.

Edzard Ernst, Universities of Exeter \& Plymouth

\section{References}

Ernst E: Media and complementary medicine. Pharm J 2005;274:21

2 Daroff RB, Griggs RG: Scientific misconduct and breach of publication ethics. Neurology 2004;62:352-353.

\section{KARGER}

Fax +497614520714 